\title{
COMPORTAMENTO HIGROSCÓPICO DA SEMENTES DE LINHAÇA (Linum usitatissimum L.).
}

\author{
G.Z. Campos e J.A.G. Vieira* \\ Universidade Estadual Paulista, Departamento de Engenharia e Tecnologia de Alimentos \\ *e-mail jantonio@ibilce.unesp.br
}

\begin{abstract}
RESUMO
Avaliou-se o comportamento higroscópico da semente de linhaça. Obtive-se dado de equilíbrio de sorção de umidade a 40,50 e $60^{\circ} \mathrm{C}$, através de um método estático, onde recipientes de $500 \mathrm{~mL}$ contendo soluções saturadas de sais foram utilizados como ambientes geradores de umidades relativas constantes, na faixa de 29 a $80 \%$. Os parâmetros dos modelos de: GAB, GAB modificada, BET, Henderson e Oswin, foram ajustados aos dados experimentais. O desvio relativo entre os valores experimentais e os valores estimados foi calculado para cada dado de umidade de equilíbrio, a fim de se avaliar qual equação melhor se ajustou aos dados experimentais. Dos modelos testados os que apresentaram melhores ajustes para as sementes de linhaça foram o de BET, seguidos por $\mathrm{GAB}$ e BET modificado para temperaturas de 40 e $60^{\circ} \mathrm{C}$ e para $50^{\circ} \mathrm{C}$ foram os de Henderson e Oswin.
\end{abstract}

\section{INTRODUÇÃO}

As sementes de linhaça são ricas em proteína, gordura e fibras dietéticas. Em média a sementes contém $41 \%$ de gordura, $28 \%$ de fibras dietéticas, $21 \%$ de proteína, $4 \%$ de resíduos e $6 \%$ de outros carboidratos (os quais incluiriam açúcares, ácidos fenólicos, lignana e hemicelulose). A composição de aminoácido encontrada na proteína da linhaça é similar ao da proteína de soja, que é vista como uma das mais nutritivas proteínas vegetais. Os beneficios da linhaça são atribuídos a seu óleo rico em alfa-linolênico (ALA), (LIMA, 2007). Coskuner e Karababa (2007) relatam que a composição da semente de linhaça varia de acordo com a variedade genética, meio ambiente de crescimento, processamento e métodos de análise. Geralmente o conteúdo de proteína da semente diminui conforme aumenta o teor de lipídios.

O conhecimento das propriedades envolvidas no processo de sorção da água nos alimentos é importante na desidratação em vários aspectos. Primeiro, pois as propriedades termodinâmicas dos alimentos relacionam a concentração de água no alimento com sua pressão parcial de vapor, o que é fundamental para a análise do fenômeno de transferência de massa e calor durante a desidratação. Segundo, porque elas determinam até que ponto o alimento pode ser desidratado, ou até quando é viável economicamente. Terceiro, porque com a entalpia de sorção é possível se saber a quantia mínima de energia para se remover uma determinada quantidade de água do alimento. Finalmente, pois o conhecimento 
das propriedades termodinâmicas pode ajudar na compreensão da microestrutura do alimento, assim como interpretações teóricas para fenômenos físicos que ocorrem na relação alimento-água (RIZVI, 1995).

Conhecer os fatores que interferem na sorção de água em alimentos torna-se prática importante, visto a relevância desse fenômeno no processamento industrial de alguns produtos agrícolas e a atenção que esses fatores requerem durante a modelagem desse processo. Para projeto que envolve desenvolvimento e/ou aperfeiçoamento de equipamentos utilizados no processamento de grãos, é de fundamental importância a simulação e a obtenção de informações a respeito do comportamento de cada produto durante o processo de sorção de água (ALMUHTASEB, MCMINN e MAGEE, 2002).

As isotermas de sorção são as representações gráficas do teor de água presente no alimento frente à atividade de água em condições isotérmicas, onde o material está em equilíbrio higroscópico com o ambiente em que se encontra e não existem mudanças na massa da amostra (ALMUHTASEB, MCMINN e MAGEE, 2002). Elas têm aplicação na predição do tempo de secagem, da vida de prateleira, na determinação do tipo de embalagem e na caracterização do produto, inclusive quando o mesmo é constituído por componentes de atividades de água diferentes. Na condição de equilíbrio, a atividade de água do alimento se iguala à umidade relativa do ambiente onde o mesmo se encontra. Nessa condição, o alimento não ganha nem perde água. A relação entre atividade de água e a umidade relativa de equilíbrio permite prever quais alimentos irão ganhar ou perder umidade, quando forem expostos a um ar com determinada umidade relativa.

O comportamento higroscópico de diversos produtos agrícolas tem sido estudado por vários pesquisadores, que descrevem modelos diferenciados para expressar o teor de água de equilíbrio em função da temperatura e umidade relativa do ar (RESENDE, 2006). Sendo o objetivo deste trabalho a determinação experimental do comportamento higroscópico das sementes de linhaça e ajuste dos modelos empíricos.

\section{METODOLOGIA}

As sementes de linhaça foram adquiridas no comércio local e apresentaram uma umidade de $12 \%$ (bu). Uma parte foi umidificada até atingir 30\% de umidade (bu) e a outra seca até $5 \%$ de umidade (bu). Após repouso para uniformidade de umidade foram colocadas $5 \mathrm{~g}$ nos recipientes contendo os sais, visando a determinação da umidade de equilíbrio. As amostram foram preparadas em triplictas e pesadas periodicamente até atingirem peso constante. Foram utilizados seis sais em três diferentes temperaturas (40, 50 e $60^{\circ} \mathrm{C}$ ). As atividades de água das soluções saturadas dos sais usados para cada temperatura utilizada foram calculadas pelas equações proposta por (RIZVI, 2005).

Com o intuito de prever o comportamento das isotermas, diversos autores propuseram modelos de ajuste de isoterma de sorção. Os modelos usados neste trabalho são apresentados na Tabela 1. 
Tabela 1. Modelos empíricos utilizados na predição de isotermas de sorção.

\begin{tabular}{|c|c|c|}
\hline Equação & Modelo & Referência \\
\hline Henderson & $m=\left[\frac{-\ln \left(1-a_{w}\right)}{a}\right]^{\frac{1}{b}}$ & (CHIRIFE e IGLESIAS,1978) \\
\hline Oswin & $m=a\left[\frac{a_{w}}{1-a_{w}}\right]^{b}$ & (CHIRIFE e IGLESIAS,1978) \\
\hline GAB & $m=\frac{m_{0} \cdot c \cdot k \cdot a_{w}}{\left[\left(1-k \cdot a_{w}\right) \cdot\left(1+(c-1) \cdot k \cdot a_{w}\right)\right]}$ & (MAROOULIS et al., 1988) \\
\hline BET & $m=\frac{m_{0} \cdot c \cdot a_{W}}{1-a_{W}}\left(\frac{1-(n+1) \cdot a_{w}^{n}+n \cdot a_{w}^{n+1}}{1-(1-c) \cdot a_{w}-c \cdot a_{W}^{n+1}}\right)$ & (PARK e NOGUEIRA, 1992) \\
\hline BET mod. & $m=\frac{m_{0} \cdot c \cdot a_{w}}{\left[\left(1-k \cdot a_{w}\right) \cdot\left(1+(c-k) \cdot a_{w}\right)\right]}$ & $\begin{array}{l}\text { (JAAFAR } \\
\text { MICHALOWSKI, 1990) }\end{array}$ \\
\hline
\end{tabular}

\section{RESULTADOS E DISCUSSÃO}

Os dados de sorção de umidade para a linhaça, obtidos a 40,50 e $60^{\circ} \mathrm{C}$ em diferentes atividades de água, são apresentados na Tabela 2. Verifica-se que para uma temperatura constante as umidades de equilíbrio aumentam com o aumento da atividade de água $\left(\mathrm{a}_{\mathrm{w}}\right)$.

As isotermas de sorção de umidade para as sementes de linhaça apresentam o formato sigmoidal, comportamento típico de isotermas do tipo II de acordo com a classificação da IUPAC, sugerindo a existência de umidades adsorvidas em multicamadas, características de produtos agrícolas. Observa-se que o conteúdo da umidade de equilíbrio da sorção da semente para $a_{w}>0,65$ cresceu com o aumento da temperatura a uma atividade de água constante, indicando que as sementes se tornam mais higroscópicas, comportamento este, inverso ao observado por Valente (2011) para curvas de dessorção da linhaça. Verificase também que para $a_{w}>0,60$ as isotermas para todas as temperaturas estudadas apresentam comportamento exponencial. Esse comportamento sugere que a partir desse valor um pequeno aumento na umidade relativa do ambiente propicia um considerável acréscimo na umidade de equilíbrio das sementes de linhaça comprometendo a qualidade de armazenamento em locais em que a umidade relativa seja acima de $60 \%$ (VALENTE, 2011).

Os dados experimentais do teor de água de equilíbrio foram ajustados através de cinco modelos matemáticos, conforme sumarizado na Tabela 3. Foi feito o uso de regressão não linear utilizando-se o processador OriginPro 8. Os valores dos parâmetros obtidos para os modelos ajustados nas diferentes temperaturas, bem como os 
respectivos valores dos coeficientes de determinação $\left(r^{2}\right)$ se encontram na Tabela 3.

Tabela 2. Umidade de equilíbrio para a semente de linhaça em função da temperatura e da atividade de água.

\begin{tabular}{rcccccc}
\hline Sal & $\mathbf{a w 4 0}^{\circ} \mathbf{C}$ & Xeq40 ${ }^{\circ} \mathrm{C}$ & $\mathbf{a w 5 0}^{\circ} \mathbf{C}$ & Xeq50 ${ }^{\circ} \mathrm{C}$ & $\mathbf{a w 6 0}^{\circ} \mathbf{C}$ & Xeq60 ${ }^{\circ} \mathrm{C}$ \\
\hline $\mathrm{MgCl}_{2}$ & 0,313 & 0,021 & 0,304 & 0,025 & 0,295 & 0,028 \\
$\mathrm{~K}_{2} \mathrm{CO}_{3}$ & 0,433 & 0,042 & 0,427 & 0,045 & 0,421 & 0,047 \\
$\mathrm{NaBr}$ & 0,532 & 0,045 & 0,509 & 0,055 & 0,496 & 0,056 \\
$\mathrm{NaNO}_{2}$ & 0,614 & 0,067 & 0,588 & 0,071 & 0,565 & 0,074 \\
$\mathrm{NaCl}$ & 0,734 & 0,076 & 0,718 & 0,083 & 0,703 & 0,092 \\
$\mathrm{KCl}$ & 0,806 & 0,090 & 0,751 & 0,098 & 0,751 & 0,106 \\
\hline
\end{tabular}

Tabela 3. Valores dos parâmetros dos modelos de isotermas de linhaça em diferentes temperaturas.

\begin{tabular}{|c|c|c|c|c|c|c|c|c|}
\hline Modelo & $T^{a}$ & $\mathrm{~A}$ & $\mathrm{~b}$ & $\mathrm{~m}_{\mathrm{o}}$ & $\mathrm{C}$ & $\mathrm{k}$ & $\mathrm{N}$ & $r^{2}$ \\
\hline \multirow{3}{*}{ Henderson } & 40 & 50,049 & 1,426 & - & - & - & - & 0,968 \\
\hline & 50 & 17,948 & 1,093 & - & - & - & - & 0,932 \\
\hline & 60 & 14,831 & 1,058 & - & - & - & - & 0,986 \\
\hline \multirow{3}{*}{ Oswin } & 40 & 0,049 & 0,439 & - & - & - & - & 0,937 \\
\hline & 50 & 0,050 & 0,602 & - & - & - & - & 0,920 \\
\hline & 60 & 0,054 & 0,623 & - & - & - & - & 0,971 \\
\hline \multirow{3}{*}{ GAB } & 40 & - & - & 13,048 & 0,490 & 0,136 & - & 0,977 \\
\hline & 50 & - & - & 10,782 & 0,020 & 0,332 & - & 0,915 \\
\hline & 60 & - & - & 4,814 & 0,044 & 0,360 & - & 0,988 \\
\hline \multirow{3}{*}{ BET } & 40 & & & 68,500 & 0,001 & - & 1,302 & 0,979 \\
\hline & 50 & - & - & 22,089 & 0,002 & - & 1,857 & 0,917 \\
\hline & 60 & - & - & 26,463 & 0,002 & - & 1,948 & 0,992 \\
\hline \multirow{3}{*}{$\begin{array}{r}\text { BET } \\
\text { modificada }\end{array}$} & 40 & - & - & 12,615 & 0,007 & 0,136 & - & 0,977 \\
\hline & 50 & - & - & 9,194 & 0,008 & 0,332 & - & 0,915 \\
\hline & 60 & - & - & 11,650 & 0,006 & 0,356 & - & 0,988 \\
\hline
\end{tabular}

\section{CONCLUSÃO}

Para as temperaturas de 40 e $60^{\circ} \mathrm{C}$ os melhores modelos ajustados foram BET, seguidos por GAB e BET modificada e para $50^{\circ} \mathrm{C}$ foram Henderson e Oswin. A umidade de equilíbrio diminui com temperatura, indicando mudanças nos mecanismos de interação da água com os sítios de superfície do produto, ou nos próprios sítios. 


\section{REFERÊNCIAS}

Al-MUHTASEB, A. H.; MCMINN, W. A. M.; MAGEE, T. R. A. Moisture sorption isotherm characteristics of food products: a review. Food and Bioproducts Processing, v.80, p.118-128, 2002.

BASTOS, S. M. C. Propriedades termodinâmicas de adsorção de água de dois genótipos de arroz vermelho. Dissertação de Mestrado, Universidade Estadual de Goiás. Anápolis, p133, 2009.

CHIRIFE, J.; IGLESIAS, H. A. Equations for fitting water sorption isotherms of foods: Part 1 - A review. Journal of Food Technology, v.13, 159-174,1978.

COSKUNER,Y.; KARABABA, E. Some physical properties of flaxseed (Linumusitatissimum L.). Journal of Food Engineering, v.78, p.1067-1073, 2007.

JAAFAR, F.; MICHALOWSKI, S. Modified BET equation for sorption/desorption isotherms. Drying Technology, v.8, p.811827,1990 .

LIMA, C. C.. Aplicação das Farinhas de Linhaça (Linum usitatissimum L.) e Maracujá (Passiflora edulis Sims f. flavicarpa Deg.) no Processamento de Pães com Propriedades Funcionais. Dissertação de Mestrado, Universidade Federal do Ceará, Fortaleza. p.97,2007.
MAROULIS, Z. B. et al. Application of the GAB model to the sorption isotherms for dried fruits. Journal of Food Engineering, v.7, p.63-70,1988.

PARK, K. J.; NOQUEIRA, R. I. Modelos para ajuste de isotermas de sorção de alimentos. Engenharia Rural, Piracicaba, v.3 p. 80-6,1992.

RESENDE, O. Isotermas e calor isostérico de sorção do feijão. Ciência e Tecnoogia.de Alimenostos, Campinas, v. 26, p.626631,2006 .

RIZVI, S. S. H. Thermodynamic Properties of Foods in Dehydration. In Engineering Properties of Ffoods, v.25, p.239-326,2005.

RIZVI, S. S. H. In M. A. RAO \& S.S.H. RIZVI (Eds.), Engineering Properties of Foods. New York: Academic Press, 1995.

VALENTE, M. C. C. Avaliação das condições de secagem no rendimento e na qualidade do óleo de linhaça (Linun usitatissimum L.). Dissertação de Mestrado, Universidade Federal do Pará, Belém, p.123 2011.

\section{AGRADECIMENTO}

À FUNDUNESP pelo auxílio financeiro para a realização do trabalho e apresentação do mesmo. 